\title{
A successful Laparoscopic surgery for multiple hydatid cysts ( 7 cysts) of liver : Case Report
}

\author{
Sameer Ibrahim Hasan \\ Department of Surgery, College of Medicine, University of Mosul , Mosul , Iraq \\ Correspondence: sameeribsaffar@uomosul.edu.iq
}

(Ann Coll Med Mosul 2021; 43 (2):212-215).

Received: 21 ${ }^{\text {th }}$ Sept. 2021; Accepted: $22^{\text {th }}$ Dece. 2021.

\begin{abstract}
Case report : To the best of our knowledge this could be the first report of a successfully performed laparoscopic surgery for female patient having had multiple liver hydatid cysts ( 7 in number) in both lobes of liver.

Background: Laparoscopic hydatid surgery ( LHS) was almost gaining acceptance all over the world. But still there are contraindications to this approach of particular are those with multiple cysts $(>3 \text { cysts })^{1}$.On reviewing the literature most of the reports of LHS were for patients with solitary hydatid cyst and exceptionally for a maximum of three cysts. Herein an initial effort to expand the application of LHS in managing multiple hydatid cysts of liver $(>3)$ with all the advantages of laparoscopic approach; less pain, good cosmetic results, rapid recovery and less complications.
\end{abstract}

Keywords : Laparoscopic, Hydatid, Liver .

$$
\begin{aligned}
& \text { عملية ناجحة لرفع اكياس مائية متعددة في الكبا (V أكياس ) } \\
& \text { بالمنظار الجراحي : تقرير حالة مدئة } \\
& \text { فرع الجر احة ، كلية الطب ، جمير ابر اهيم حسن الموصل ، الموصل ، العراق } \\
& \text { كلا فصي الكبد (عدد V) . } \\
& \text { الكلمات المفتاحية : منظلار ، أكياس مائية ، الكبد . }
\end{aligned}
$$

\section{INTRODUCTION}

chinococcosis is the most frequent cause of liver cysts in the world ${ }^{1,2}$. Hydatid disease is endemic mainly in the Mediternnean countries, the Middle East, South America, India, and northern China $^{3}$. Liver echinococosis is endemic in our country and still it represent a disease that can be challenging for the surgeon ${ }^{4}$. It is caused by parasite called Echinococcus Granulosis that inhabit the intestine of dogs and canines as a definitive host. Humans are accidental intermediate hosts due to ingestion of the parasitic eggs ${ }^{5}$. The most common sites are the liver account for $60 \%$,the lung account for $30 \%$ although it may develop at other sites including kidney,bone,brain and heart ${ }^{6}$.

Surgery remains the treatment of choice for the majority of cases of Hydatid liver cyst despite significant economic costs, advances in medical treatment, and interventional radiology ${ }^{6-9}$.The main principle in any hydatid cyst surgery is to eliminate the scolices by evacuation without spillage, to check for any biliary communication, to sterilize and to obliterate the residual cavity ${ }^{7}$. 
Laparoscopic approach follow the same rules as in conventional surgery. In spite of advancement in the laparoscopic techniques but still there are contraindications to LHS like; those with intraparenchymal cysts, cysts at risky site (e.g. near the porta hepatis), complicated cysts, and multiple cysts $(>3)$ which are not candidates for laparoscopic approach

\section{The Case}

A female 45 years old female housewife resident in Mosul, presented with long history of upper abdominal discomfort. She gave no history of fever, jaundice. Her appetite was good with normal bowel motion. There was no history of loss of weight. There was no clear history of animal contact. On examination, she looked healthy, And she had neither anaemia nor jaundice. Her abdomen was of normal contour, soft, with palpable liver. Ultrasound examination of abdomen showed the presence of multiple cystic lesions in both lobes of liver, more than 3 in number. For more confirmation of the diagnosis and also for more accurate number and localization of the cysts a computerized tomography was ordered. CT scan revealed the presence of multiple hypodense lesions in both lobes of liver, of variable sizes; the largest one was $7 \mathrm{~cm}$ in diameter. The cysts were distributed in both lobes of liver particularly in segments 2,4,6, and 8, Figure 1.

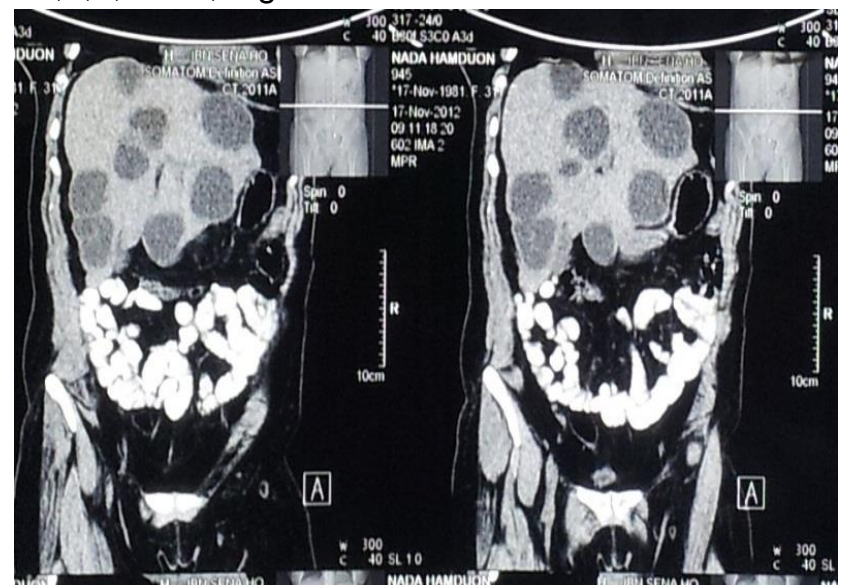

Figure 1: CT scan of abdomen revealed multiple hypodense cystic lesions in both lobes of liver.

Serological investigations for hydatid disease was not done because of its unavailability in our locality. The patient given a chance of medical therapy and Albendazol 200mg t.i.d. was given for three months. At the end of this period MRI examination of abdomen was done and revealed more or less the same findings as that of the CT scan prior to therapy, Figure 2.

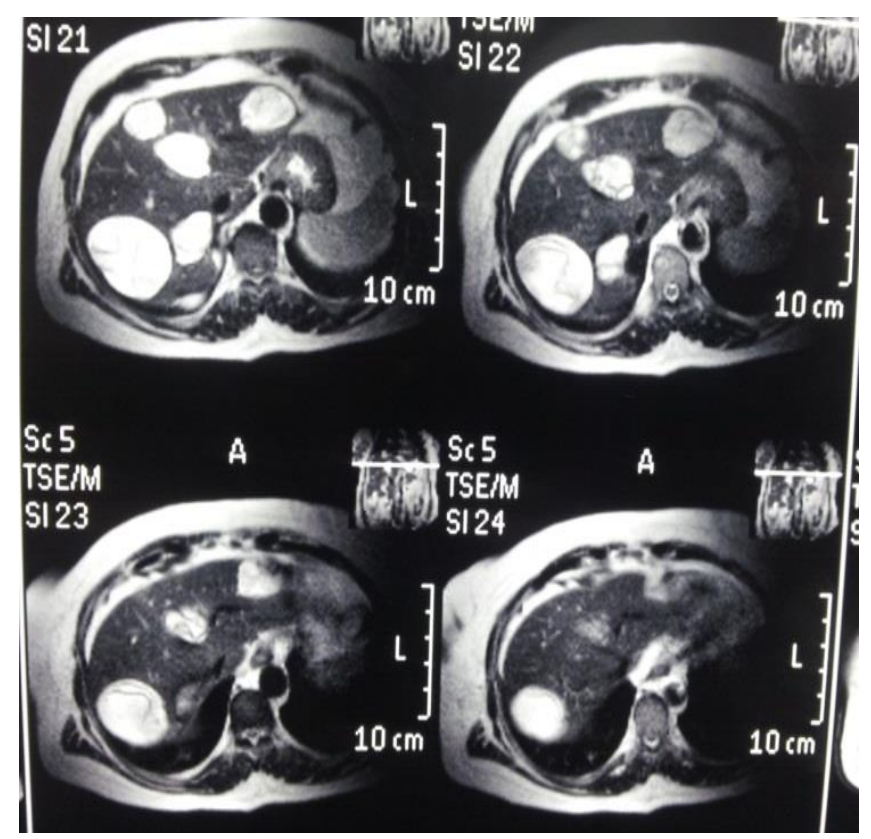

Figure 2: MRI examination showing multiple cysts in liver

More close view of MRI showed the characteristic picture of water lily sign which is pathognomonic of hydatid cyst with detached laminated membrane, Figure 3.

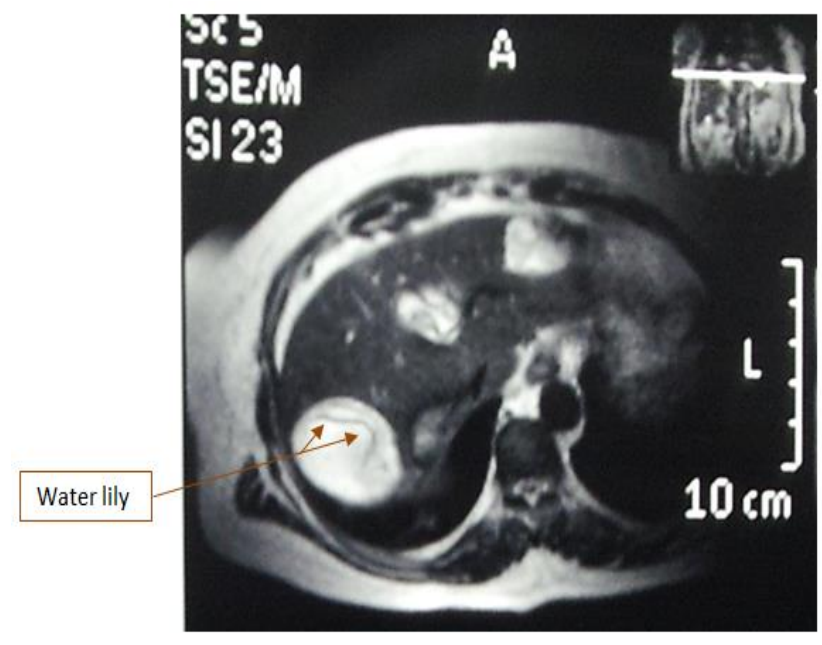

Figure 3: MRI examination showing water lily appearance.

A decision for surgical treatment was discussed with the patient and an informed consent was taken for laparoscopic management. Chest $X$ ray showed no concomitant pulmonary hydatid, Figure 4. 


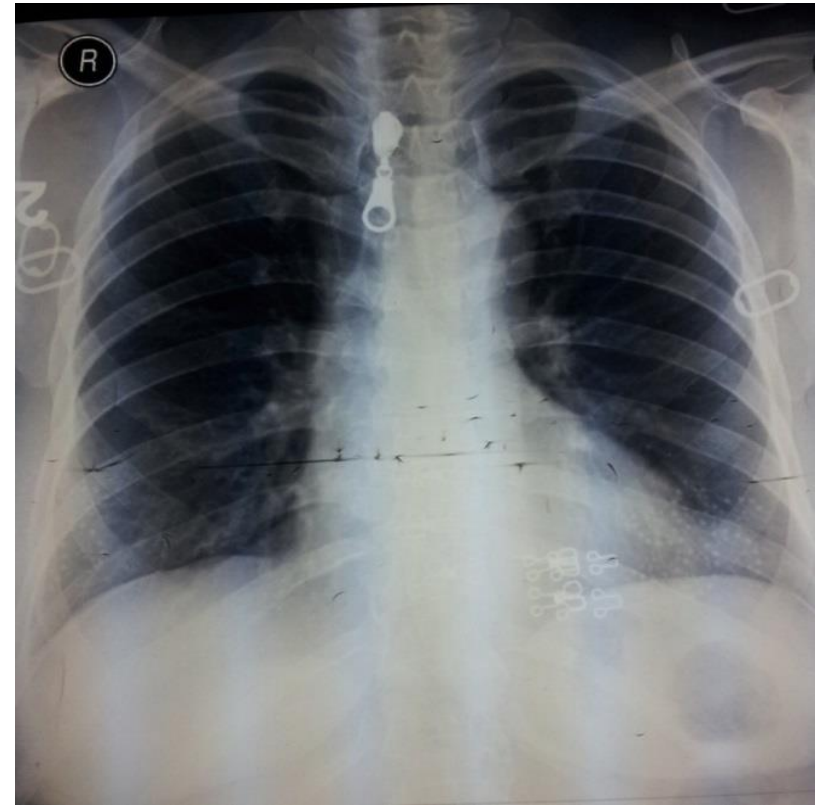

Figure 4 : Chest $\mathrm{X}$ ray revealed clear lungs

\section{Operative Procedure}

The operation conducted under general anaesthesia and muscle relaxation. Open laparoscopy performed through the umbilical cicatrix and pneumoinsufflation started through the $10 \mathrm{~mm}$ cannula. Initial exploratory laparoscopy done and the 7 cysts of liver were seen distributed in both lobes of liver, Figure 5 .
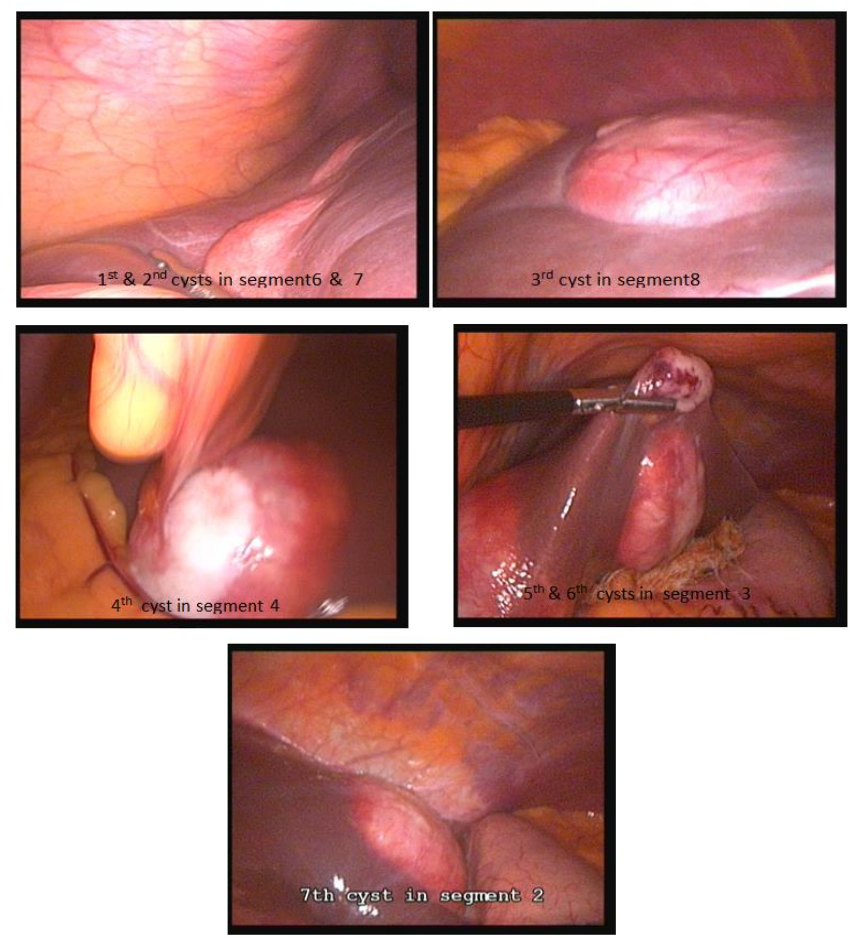

Figure 5, Operative view of the cysts on the liver
All the cysts were manipulated like in conventional open surgery; initial aspiration of cysts and injection of scolicidal agent (Povidone iodine $10 \%$ ), with great care taken to prevent spillage by using suction guard near the aspiration needle, figure 6 .
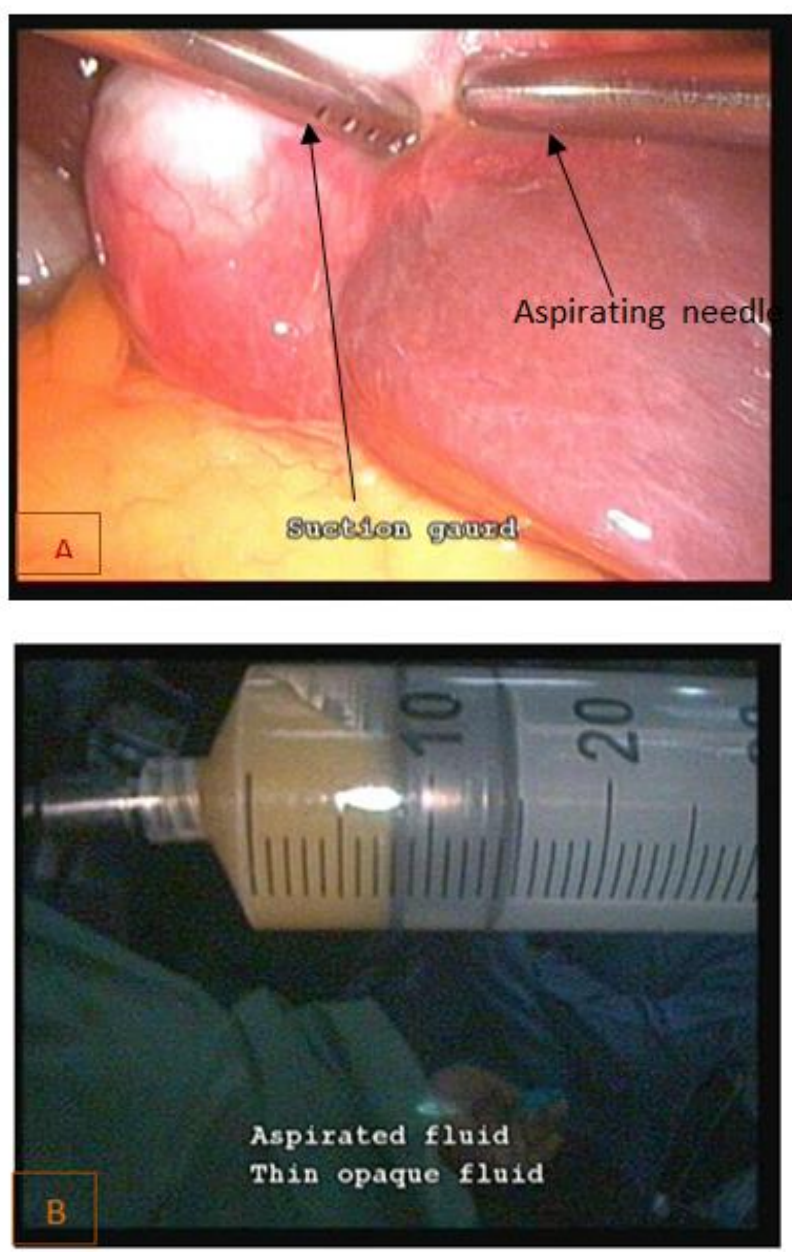

Figure $6,(A)$ Needle aspiration with suction guard ,(B) Aspirated cystic fluid

The ectocyst was opened and the contents sucked out. The cysts were found to be dead probably as an effect of Albendazol, as they were not tense, with opalescent fluid, and macerated laminated membrane. The laminated membrane of all cysts were taken out by suction. Checking of residual cavities was performed by intracavitory telescope looking for any billiaray communication or missed cyst contents. Two tube drains were put in the right and left subphrenic spaces. On the $2^{\text {nd }}$ postoperative day the patient was healthy, and started oral intake. Ultrasound examination was performed in the fifth postoperative day and revealed no collections, so the drains were removed and the patients discharged home. The patient was seen one week later, having no 
complaints, with clean wounds, Figure 7. The patient was continued on albendazol $200 \mathrm{mg}$ t.i.d. for one month. The patient was followed for 3 months, having no complaints and monthly ultrasound examinations revealed no collections.

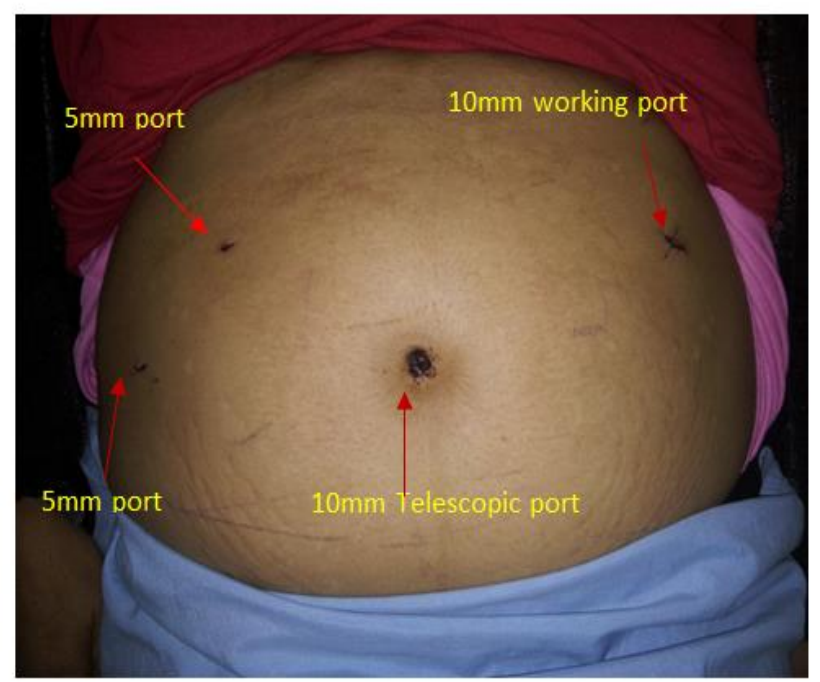

Figure 7 : Clean Port wounds 7 days after surgery

\section{Comment}

In our locality till now the majority of the hydatid cysts of the liver have been managed by conventional open surgical techniques. LHS was introduced since the beginning of this century, applied for certain selected patients with promising initial results ${ }^{6}$. The same principles of conventional liver hydatid cyst surgery, including inactivation of scolices, prevention of spillage, elimination of viable elements of the cyst, and management of the residual cavity were applied in the laparoscopic approach . As elsewhere LHD has its own limitations and in particular those with multiple cysts (>3 cysts), which were not operated upon laparoscopically ${ }^{1,10}$.

LHS was introduced in our locality since 2000. After standardization of the technique and accepting good experience in this mode of surgery, we started to apply LHD more widely and patients with 2-3 cysts were operated upon with good results.

The outcome of surgery was excellent with no morbidity during the follow up period. The patient was followed for up to one year after surgery having no any complaints and ultrasound checking was done on each visit with no evidence of recurrence of the cyst.

This successful procedure may open the window for more wider application of laparoscopy in the management of hydatid disease of liver.

\section{REFERENCES}

1.Metin Ertem,Tayfun Karahasanoglu, Nihat Yavuz, Sabri Erguney. Laparoscopically Treated Liver Hydatid Cysts. . Arch Surg. 2002;137:1170-1173

2. Rinaldi F, Brunetti E, Neumayr A, Maestri M, Goblirsch S, Tamarozzi F. Cystic echinococcosis of the liver: A primer for hepatologists. World $J$ Hepatol. 2014;6(5):293-305. doi:10.4254/wjh.v6.i5.293.

3. Tselentis J, Karpathios T, Fretzayas A, Korkas A, Nickolaidio P, Matsaniotis N. Hydatid disease in asymptomatic young carries in northern Greece. Am J Trop Med Hyg 1983;32(6):1462-3.

4.Benyan AK, Mahdi NK, Abdul-Amir F, Ubaid O. Second reported case of multilocular hydatid disease in Iraq. Qatar Med J. 2013;2013(1):2829. Published 2013 Nov 1. doi:10.5339/qmj.2013.5

5.Bickel A, Daud G, Urbach D. Laparoscopic approach to hydatid liver cysts. Is it logical? Physical, experimental, and practical aspects. Surg Endosc. 1998;12:1073-7.

6. Ertem M, Uras C, Karahasanoglu T. Laparoscopic approach to hepatic hydatid disease. Dig Surg. 1998;15:333-6.

7. Verma GR, Bose SM. Laparoscopic treatment of hepatic hydatid cyst. Surg Laparosc Endosc. 1998;8:280-2.

8. Hanan R Rihani, Basem A El- Nabulsi,Abdul Aziz M Ziadat, Basheer $R$ AlJarrah.Laparoscopic approach to liver hydatid cyst. Is it safe?.JRMS June 2005; 12(2):69-71.

9. Niscigorska J, Sluzar T, Marczewska M et al. Parasitic cysts of the liver -practical approach to diagnosis and differentiation. Med Sci Monit. 2001;7(4):737-741.]

10. Acarli K. Controversies in the laparoscopic treatment of hepatic hydatid disease. HPB (Oxford). 2004;6(4):213-221. doi:10.1080/13651820410024003 